\title{
REFLEXÕES E INTERPRETAÇÕES SOBRE A PARTICIPAÇÃO E A REPRESENTAÇÃO EM CONSELHOS GESTORES DE POLÍTICAS PÚBLICAS ${ }^{1}$
}

\author{
Marcelo Eliseu Sipioni
}

Marta Zorzal e Silva

\begin{abstract}
RESUMO
O presente ensaio debruça-se sobre a literatura recente acerca do tema da representação em conselhos gestores de políticas públicas. Várias são as análises feitas por diversos autores sobre a temática, porém, há necessidade de reflexão sobre a confluência que muitas destas ideias apresentam, de forma a contribuir para um consenso mínimo (obviamente não definitivo) sobre as possibilidades e os limites do exercício democrático em conselhos gestores, necessidade que este artigo objetiva responder, ao menos em parte. Para desenvolvermos esta análise, revisamos a literatura com vista a buscarmos autores de diversas áreas do conhecimento que de alguma forma tratam em seus trabalhos do tema da teoria democrática e da participação e representação, buscando observar contrapontos e convergências em suas ideias para posteriormente lançarmos questões minimamente consensuais sobre o tema. Os autores analisados deixam claro que os discursos que permeiam as questões relativas à participação è à representação têm como pano de fundo teorias democráticas distintas que durante quase todo o século passado conflitam em busca de hegemonia: democracia representativa e democracia participativa. Sendo assim, os ideais que alicerçam os conceitos aqui estudados são expressos de maneiras diferentes, de acordo com a teoria que a embasa. O fato é que participação e representação podem ser exercidos tanto em uma democracia representativa quanto em uma democracia participativa. Contudo, apresentam sentidos e práticas diferentes. Os conselhos gestores de políticas públicas são, por excelência, um local criado para o exercício da democracia participativa. Porém, ali é exercida participação indireta, via representação. Este conceito, por sua vez, é fortemente arraigado aos ideais da democracia representativa, levando à necessidade de se estabelecer diferenças entre representar (na democracia representativa) e representar (na democracia participativa), de forma que conselheiros representantes da sociedade civil nos conselhos gestores não repitam os equivocos da prática representativa parlamentar, sob o risco de conduzir a representação nestas instâncias participativas a um distanciamento que prejudicaria o exercício da democracia participativa em nosso país. Parece-nos evidente a importância de se estabelecer uma relação entre representantes e representados que os aproxime. Desta forma, temas como a prestação de contas e a própria forma de escolha do representante por sua entidade parecem exercer um protagonismo interessante para legitimar a representação e torná-la diferente da representação parlamentar. Apesar dos entraves observados para a efetivação de uma verdadeira democracia participativa, os conselhos gestores alimentam uma cultura politica em transformação no Brasil, a cultura da participação, capaz de ocupar o lugar de nossa histórica cultura de submissão do povo ao poder das elites.
\end{abstract}

PALAVRAS-CHAVE: participação social; representação; conselhos gestores.

\section{INTRODUÇÃO2: O DEBATE ATUAL SOBRE PARTICIPAÇÃO E REPRESENTAÇÃO}

A existência, no cenário político brasileiro, de instituições participativas demandadas em grande

\footnotetext{
1 O presente artigo compõe parte da dissertação intitulada"Legitimidade da representação em conselhos de saúde: o caso do Conselho Municipal de Saúde de VitóriaES" defendida junto ao Programa de Pós Graduação em Saúde Coletiva da Universidade Federal do Espírito Santo (PPGSC/UFES) por Marcelo Eliseu Sipioni.

2 Gostaríamos de agradecer aos pareceristas anônimos da Revista de Sociologia e Política por sua contribuição para este artigo.
}

parte pela pressão popular durante o Regime Militar (1964-1985) gerou um aumento substancial na participação da sociedade civil na tomada de decisões relativas às políticas públicas. Assim, instituídos legalmente (no caso dos conselhos gestores de políticas públicas) ou sob políticas governamentais de partidos de esquerda, especialmente do Partido dos Trabalhadores (no caso do Orçamento Participativo), essas formas institucionais alargaram consideravelmente o pressuposto democrático do Brasil pós-1988. Instaurou-se, assim, um modelo híbrido de democracia no Estado brasileiro (AVRITZER, 2006) em que representação e participação estão combinadas. 
Tal combinação nos dá uma pista do quão interessante torna-se a discussão do aumento da participação da sociedade civil nas decisões sobre as políticas sociais. Com a inserção em massa desses novos atores em instâncias de tomada de decisões, surgem também novas formas de representação ligadas à sociedade civil. Formas essas que devem ser discutidas e analisadas diferentemente dos enfoques dados à representação parlamentar (AVRITZER, 2007), mesmo porque, como nos lembra Mendes (2007), é a esta forma - eleitoral que se atribui a crise da representação política atualmente, já que ela tornou-se pouco eficaz e deslegitimada ao longo da vigência do Estado-Nação. Tal crise evidencia-se em três aspectos, expostos por Miguel (2003): comparecimento eleitoral em declínio (em países onde o voto não é obrigatório), desconfiança aumentada em relação às instituições políticas e, por fim, esvaziamento partidário. As críticas que tentam dar luz a tal crise, como nos lembra Pinto (2004), referem-se a formas alternativas de participação, no sentido de substituir a representação e de criar instrumentos que favoreçam a accountability ou prestação de contas. Contudo, Mendes (2007) alerta-nos para um possível agravamento dessa crise caso haja uma consonância desses novos formatos institucionais de representação com o modelo tradicional.

Vale ressaltar que o pano de fundo para essa discussão - a representação da sociedade civil em instâncias participativas - remete-nos inevitavelmente à teoria democrática em voga, que mesmo não sendo foco principal da análise aqui sugerida, merece certa atenção. $O$ fato é que houve uma disputa intensa durante o século XX entre várias concepções de democracia, resumidas em dois campos distintos politicamente: a Democracia Representativa e a Democracia Participativa (que serão resumidamente descritas a posteriori). Diversos autores vêm, contudo, assumindo que, longe de serem antagônicas, essas duas concepções devem ser complementares (SANTOS, 1999; SANTOS \& AVRITZER, 2002; AVRITZER, 2006; FERRAZ, 2006). Sendo assim, é na combinação entre as duas teorias que se estabelece a inevitabilidade da representação no interior de experiências de participação (LÜCHMANN, 2007).

O que se busca com tal discussão é uma normatização mínima que consiga estabelecer determinados pressupostos para o alcance da legitimidade da representação política em instituições participativas. Alguns autores que serão aqui discutidos, como Avritzer (2007), Borba e Lüchmann (2008), Gurza Lavalle, Houtzager e Castello (2006),
Lüchmann (2007; 2008), Urbinati (2006) e Young (2006), dentre outros, conseguem apontar caminhos interessantes, mesmo que por vezes conflitantes entre si, para se alcançar o objetivo do debate sobre o tema.

Contudo, como nos alerta Gurza Lavalle, Houtzager e Castello (2006), a literatura sobre esse assunto é ainda escassa. Se por um lado os teóricos da reforma democrática não cogitaram a questão da representação da sociedade civil em suas análises, os que propuseram uma reconfiguração da representação o faziam em nome de uma representação eleitoral, descartando discussões sobre a configuração da representação na democracia participativa (GURZA LAVALLE, HOUTZAGER \& CASTELLO, 2006). De todo modo, o debate é rico, crescente e promissor, requerendo constantes análises empíricas da forma como a representação política vem ocorrendo no contexto da participação da sociedade civil no país.

O objetivo deste trabalho, portanto, é reunir diferentes propostas de discussão sobre a representação política nas formas participativas de democracia, com o intuito de contribuir com esse promissor e rico debate. Dessa forma, analisaremos as discussões em torno da participação (via representação) nos conselhos gestores de políticas públicas, que configuram um interessante aspecto de discussão e análise desse campo teórico.

\section{PARTICIPAÇÃO E REPRESENTAÇÃO EM CONSELHOS GESTORES DE POLÍTICAS PÚBLICAS}

O tema da representação política, da forma como pretendemos abordá-lo neste artigo, é uma questão que tem permeado o debate desde a emergência do Estado moderno. Tendo como referência autores clássicos do pensamento político moderno, como Hobbes, Rousseau, Burke, Bentham e Stuart Mill, os autores contemporâneos tentam reinterpretar e contextualizar idéias, ora criticando-as, ora reafirmando-as (PITKIN, 1979; 2006; GURZA LAVALLE, HOUTZAGER \& CASTELLO, 2006; MENDES, 2007) $)^{3}$.

$\mathrm{Na}$ verdade, esses diversos teóricos abordaram o tema com bastante propriedade, ao tratarem da questão de como uma ordem política poderia ser constituída de forma a postar-se legítima aos cidadãos, os quais, por isso mesmo, prestariam obediência à autoridade constituída. O problema colocado era como, em um

\footnotetext{
3 Entre esses autores, Pitkin (2006) apresenta uma fantástica base de leitura a respeito da evolução do conceito de representação ao longo da história, revisitando os sentidos que lhe foram sendo atribuídos, políticos ou não.
} 
mundo marcado pela procura legítima e razoável de interesses pessoais, seria possível constituir uma autoridade legítima (governo/representação política) que pudesse ser sustentada por todos os cidadãos e qual forma ela deveria assumir. Esse é o ponto em torno do qual recorrentemente a literatura moderna e contemporânea se debruça, tentando encontrar formas e justificativas válidas e aceitas para a relação entre representantes e representados, ou seja, entre representação e soberania popular.

No debate que se segue, já no século XX, a tensão manifesta-se na negação e/ou afirmação da democracia como uma forma desejável de governo, as quais tiveram lugar na primeira metade do século $\mathrm{XX}$, com teóricos como Weber, Schmitt, Kelsen, Michels e Schumpeter. Embora a forma democrática de governo representativo tenha sido afirmada como desejável entre as duas guerras mundiais, e se tornado hegemônica a partir de então, a questão da relação entre representação e soberania popular resolveu-se por meio de mecanismos restritivos às formas de participação e soberania ampliadas, que se consubstanciou em um consenso em torno de um procedimento eleitoral para a formação de governos (AVRITZER, 2003). Tal consenso fundou-se nas proposições de Schumpeter (1984), o qual rompeu com a ideia de democracia enquanto soberania para propôla como método, ou seja, um tipo de arranjo institucional para se alcançar decisões políticas (legislativas e administrativas). Para tanto, definiu a democracia como sendo um método de produção de governos. Desse modo, sugeriu uma forma para contornar a irracionalidade das massas, reduzindo sua participação na política ao ato da produção de governos, isto é, ao voto. Às elites eleitas por esse método compete a tarefa de governar, devendo exercer todas as demais atribuições do governo capazes de gerar algum nível de racionalidade política (AVRITZER, 1996, p. 107).

No cerne das disputas teóricas e nos modelos e arranjos institucionais sugeridos à forma democrática de governo, que se sucedem até os dias hodiernos, persiste o problema da relação representação versus soberania popular. Se, por um lado, os modelos centrados na representação minimizam o problema do tamanho e da complexidade das sociedades modernas, por outro, colocam recorrentemente em pauta o tema da legitimidade da representação devido à heterogeneidade política. De fato, esse é o problema central da democracia representativa moderna, isto é, sua legitimidade e accountability em face da sociedade que a constitui.

É, portanto, em torno desses e outros questionamentos à democracia representativa que emerge, na segunda metade do século XX, um grupo de teóricos da democracia, em especial Jürgen Habermas e Joshua Cohen, os quais voltam suas reflexões para o exame da "democracia local e a possibilidade de variação no interior dos Estados nacionais a partir da recuperação de tradições participativas solapadas no processo de construção de identidades nacionais homogêneas" (SANTOS \& AVRITZER, 2002, p. 42).

Em suma, se o grupo de autores da primeira metade do século XX defende o abandono do papel da mobilização social e da ação coletiva na construção democrática, com a conseqüente supervalorização do papel dos mecanismos de representação, o grupo que emerge na segunda metade do século XX centra suas reflexões nos mecanismos restritivos à participação $\mathrm{e}$ à soberania ampliada, propondo como solução a combinação dos mecanismos de representação com os mecanismos societários de participação.

É nesse contexto que, especialmente na segunda metade do século XX, houve uma reivindicação muito forte pela institucionalização da participação da sociedade civil em nome de uma democracia participativa e deliberativa e pouco se pensou no formato em que se consideraria essa participação (GURZA LAVALLE, HOUTZAGER \& CASTELLO, 2006). Podemos pensar que, ao criticar o modelo representativo de democracia, os teóricos da democracia participativa, como Pateman (1992), temendo perder campo ao defender quaisquer formas de representação, mesmo que fossem mais inclusivas perante a representação eleitoral, e baseando-se em autores clássicos críticos, como Stuart Mill, ou mesmo totalmente avessos à representação, como Rousseau (1997), focavam sua defesa e teoria apenas na participação da sociedade, pouco aprofundando a questão inevitável do formato representativo em que iriam se configurar essas instâncias. Em outras palavras, as críticas participacionistas à concepção representativa de democracia, com todos os seus adjetivos atribuídos (FERRAZ, 2006), deixaram uma grande lacuna na teoria democrática ao não proporem análises e discussões profundas sobre a característica, também representativa, que o modelo de participação da sociedade civil iria iniciar.

Há de se entender que as críticas atuais da democracia participativa em relação à democracia representativa problematizam o fato desta referir-se a indivíduos isolados como sujeitos políticos. Para a concepção participativa, é impossível que um indivíduo isolado promova um debate político plural, diversificado, amplo, que produza mudanças políticas e institucionais na vida dos cidadãos. Ela defende, por outro lado, a incorporação de atores sociais 
coletivos aos processos decisórios, inaugurando uma nova noção de representação, que inicia possibilidades inovadoras, mas que ainda está profundamente arraigada à ideia cultural e política da representação parlamentar (FERRAZ, 2005, p. 42-43).

A democracia representativa, considerada elitista pelos teóricos participacionistas, ao reduzir ao ato do voto a participação da sociedade em seu modelo de democracia, reduz também a soberania popular a um procedimento de escolha de governos. Tal modelo, que tem em Schumpeter (1984) seu principal teórico, entende que a capacidade de decisão e debate político do povo é extremamente baixa, de modo que a sociedade deve limitar-se a autorizar uma elite técnica e qualificada a exercer o papel de gerir a máquina pública em seu nome. Posteriormente, outros autores empenharam-se em reformular essa concepção minimalista de democracia, mas sempre destacando o caráter meramente eleitoral da participação popular (BOBBIO, 2000; DAHL, 2001).

Ao mesmo tempo, diversos autores, como Santos e Avritzer (2002) e Pateman (1992), tentam rebater os conceitos minimalistas trazidos por Schumpeter, de modo a trazer às discussões sobre a democracia os conceitos de autores clássicos, como Rousseau e Mill, que pregavam uma concepção ampliada de democracia. Assim, "democracia" deve significar mais que um procedimento para formação de governos. Deve ser efetivada como substância, ou seja, como forma de liberdade e igualdade de toda uma nação, com toda a sua pluralidade, sendo, portanto, uma "forma de aperfeiçoamento da convivência humana" (SANTOS \& AVRITZER, 2002, p. 50). Pensar a democracia em termos de liberdade e igualdade requer muito mais do que definir procedimentos para a tomada de decisão, mas sim, um valor que orienta a vida (FERRAZ, 2006). Como bem nos lembram Santos e Avritzer (2002), segundo as práticas democráticas da democracia representativa, jamais seria possível que a pluralidade de atores sociais de uma nação tivesse a oportunidade de vocalizar suas demandas. Já a concepção participativa de democracia propõe exatamente essa inclusão, de forma que sua legitimidade expressa-se na idéia de que aqueles que serão afetados pelas decisões políticas devem, então, decidi-las (LÜCHMANN, 2007). As eleições têm, sim, sua importância, mas são insuficientes para englobar todas as relações de representação existentes entre Estado e sociedade (AVRITZER, 2007; SAWARD, 2008) no sentido de que pouco contribuem para o processo representativo da sociedade civil em instâncias não parlamentares (URBINATI, 2006). Em suma, a democracia participativa tem como ideia central a autodeterminação política da pluralidade social e prega pelo reconhecimento dessa pluralidade e pela criação de canais em que ela possa ser expressa (FERRAZ, 2006).

Sendo assim, orientados por estes preceitos participacionistas, os movimentos sociais da segunda metade do século XX passaram a reivindicar maior participação na tomada de decisões, requerendo, para isso, a criação de instituições participativas, novos espaços públicos (COSTA, 2002) de debate e deliberação junto ao Estado como forma de lutarem por direitos (TELES, 1994) relativos à sua cidadania. Se antes, portanto, a discussão girava em torno de distinções maniqueístas entre sociedade civil e Estado, hoje o debate salienta a sinergia dessa relação, bem como inaugura idéias a respeito dos novos espaços institucionais que surgem, em que o papel da sociedade civil se destaca, criando novas formas de representatividade (GURZA LAVALLE, 2003).

Além dessas contribuições a respeito da emergência de movimentos sociais e outras organizações civis (ONG, associações, entre outras), Ferraz (2005, p. 40) salienta ainda que: "A emergência destes novos atores sociais coletivos, com uma configuração bastante diferente da configuração de partidos políticos, colocou em xeque o processamento de conflitos, a discussão de temas públicos e a tomada de decisões nas instâncias representativas, denunciando sua incapacidade para representar eficazmente a pluralidade e diversidade de identidades e demandas emergentes e exigindo uma interlocução direta com o Estado, a construção de novas mediações e canais de diálogo".

No bojo dessa emergência, a partir da promulgação da Constituição Federal de 1988, surgem os conselhos gestores de políticas públicas nas diferentes áreas, como saúde, educação, assistência social, segurança pública, segurança alimentar e nutricional, entre outros. Considerados por diversos autores como sendo um meio promissor e carregado de possibilidades à democratização do Estado brasileiro, os conselhos gestores integram o que Avritzer (2006) chama de democracia híbrida, em que a democracia participativa estaria presente em concomitância com a democracia eleitoral ${ }^{4}$. Ferraz (2009) lembra-nos, porém, que na atuação dos conselhos gestores evidencia-se a tensão entre democracia participativa e democracia representativa, de modo que nem sempre essa tensão aponta para a complementaridade de ambas, como defendem Santos e Avritzer (2002). A autora alerta para

\footnotetext{
4 Idéia contestada por Ferraz (2005), por entender que mesmo nos espaços de participação direta (como nas primeiras etapas do OP) e indireta via representação (como nos conselhos gestores e as etapas finais do OP) há "constrangimentos, práticas clientelísticas ou hierarquização de posições” (idem, p. 50).
} 
o fato de que práticas tradicionalmente relacionadas à representação eleitoral estão presentes na gestão conselhista, entre elas o distanciamento entre representantes e representados. Isso porque, segundo a autora, os conselhos são "objeto de disputa entre modelos de democracia, projetos políticos e resolução de conflitos" (FERRAZ, 2009, p. 200). Neles estão explícitos os diversos interesses da sociedade, inclusive os que enfraquecem a democracia participativa.

É fato que nem só possibilidades vêm sendo encontradas nos resultados dos estudos sobre os conselhos gestores, mas, sobretudo, limites. Portanto, diversas críticas vêm sendo construídas referentes a esses órgãos, afirmando que, por mais que sejam considerados marcos históricos positivos, ainda não demonstram avanços significativos na afirmação da democracia brasileira ${ }^{5}$. Abers e Keck (2008), por exemplo, levantam algumas críticas em relação à atuação dos conselhos gestores e à representação que neles vem se configurando e concluem que: "Como arena peculiar para a interação entre um conjunto fragmentado de atores sociais com origens e interesses diversos, os conselhos gestores podem não ser espaços adequados para representação [...]. No entanto, eles podem ser espaços vivos para a produção de novas definições e práticas para a resolução de problemas" (idem, p. 110).

A interessante análise de Ferraz (2009) sobre o olhar dado aos conselhos gestores nos debates contemporâneos parece-nos bastante pertinente neste momento. Segundo a autora, um dos motivos pelos quais avaliações negativas são atribuídas aos conselhos gestores refere-se ao fato de o olhar sobre eles lançado ser equivocado. Analisar os conselhos gestores sob a perspectiva de ruptura radical com mecanismos tradicionais de representação impossibilita a visão de que a participação nesses espaços não é direta, como idealizam os atores sociais e autores críticos sobre o tema, mas realiza-se nos moldes da democracia representativa. Muda-se a relação entre representantes e representados (mais orgânica nos novos espaços institucionais de participação). Porém, o tipo de vínculo criado é o de representação, ou seja, também nesse caso a alguém é atribuída a função de representar seus pares. A autora conclui, portanto, que é errado analisar os conselhos gestores como instituições onde a participação direta se efetiva. Neles, a participação é indireta, via representação.

\footnotetext{
5 Dagnino (2002, p. 163) alerta-nos para o fato de que essas avaliações negativas, em relação aos estudos de avaliação dos espaços públicos de participação da sociedade civil, devem-se, em grande medida, ao tom demasiado otimista que sua constituição trouxe desde o início.
}

Também quando comparados com os Orçamentos Participativos, os conselhos gestores apresentam determinados limites ao alargamento da democratização (LÜCHMANN, 2007; AVRITZER, 2008), seja por possuírem ambiguidades em relação aos seus representantes, seja pela tênue relação entre demandaresolução, de forma que esta última tende a limitar consideravelmente a motivação à participação nos conselhos (LÜCHMANN, 2007).

Assim, para afirmarem-se como mecanismos alternativos de gestão democrática, os conselhos gestores devem ser capazes de fugir da lógica paradoxal de democracia eleitoral, como muito bem coloca Lüchmann (2002), até porque esse modelo eleitoral de democracia vem sendo apontado como responsável pela crise da representação política (MENDES, 2007), uma vez que não integra as diversas formas de advocacia e participação de origem extraeleitoral (AVRITZER, 2007). Neste mesmo trabalho, Avritzer propõe uma reformulação do conceito de representação que seja capaz de reforçar tanto seu elemento eleitoral quanto o não eleitoral, de modo a ser operada por múltiplas soberanias, e não uma apenas.

Cabe aqui abrirmos um parêntese importante para que fique claro ao leitor que os autores aqui trabalhados vêm afirmando uma relação estreita entre representação e democracia, ao contrário de teóricos clássicos radicais, como Rousseau (PITKIN, 1979; 2006; MENDES, 2007). Na análise de Saward (2008), por exemplo, o autor é enfático ao dizer que apenas a representação pode tornar possível a democracia e faz uma crítica a essa mesma representação que, segundo ele, vem substituindo a democracia, e não lhe servindo, na medida em que o autogoverno vem sendo substituído por um arranjo cada vez mais excludente de democracia representativa (idem). Para esse autor, bem como para Urbinati (2006), a representação não deve ser considerada como uma alternativa second best à democracia direta, mas sim deve ser considerada como "um modo de a democracia recriar constantemente a si mesma e se aprimorar" (idem). Portanto, mesmo sob a possibilidade de participação direta, a representação formal é mais viável (YOUNG, 2006).

Assim, devemos partir do pressuposto de que democracia e representação não são antitéticas, mas, sim, mantêm uma relação de necessidade da primeira para com a segunda (URBINATI, 2006; YOUNG, 2006). A questão central deve ser o entendimento de que a idéia de representação de que estamos tratando, que envolve a representação da sociedade civil, mesmo que se baseie em pressupostos da representação em 
legislaturas e parlamentos, deve criar para si uma teoria própria (URBINATI, 2006) ${ }^{6}$, que segundo Gurza Lavalle, Houtzager e Castello (2006) foi negligenciada nos apanhados teóricos sobre democracia e representação política. Sobre esse objetivo é que vêm se debruçando os diversos autores aqui contemplados.

Inicialmente, seguindo as idéias de Young (2006), devemos entender a representação de maneira menos utópica e idealizada, assumindo que essa deve estabelecer-se em virtude de semelhantes perspectivas sociais, e não sob o pressuposto da identidade dos representados para com os representantes, que dividiriam as mesmas opiniões e os mesmos interesses. Para a autora, dizer que a representação deve acontecer por identidade é dizer que ela é impossível de ser efetivada, pois para tal é necessário que um único representante identifique-se com um imenso número de representados, o que humanamente é impossível. Young (idem) argumenta que é racionalmente correto pensar que representantes e representados são, sim, diferentes, devem ser separados ${ }^{7}$, e que essa diferenciação entre os grupos "propicia recursos para um público democrático comunicativo que visa estabelecer a justiça, uma vez que pessoas diferentemente posicionadas têm diferentes experiências, histórias e compreensões sociais, derivadas daquele posicionamento. A isso chamo perspectiva social" (idem, p. 162; grifos no original).

A representação por perspectivas é mais democrática, segundo Young, porque perspectivas "não podem ser facilmente pensadas como conflitantes" (YOUNG, 2006, p. 169), como são as opiniões e os interesses. Ela acrescenta ainda que tal concepção de representação favorece uma inclusão de diferentes pessoas no processo decisório, pois retoma a ideia de uma "determinada linha de narrativa histórica ou expressa um certo modo de olhar as posições de outrem" (idem, p. 167).

\footnotetext{
6 Gurza Lavalle, Houtzager e Castello (2006), analisando formas presuntivas de representação da sociedade civil, contudo, encontraram um ainda forte traço tradicional na representação da sociedade civil, de forma a manterem um estreito relacionamento com canais tradicionais da política, como os partidos políticos. Também Fuks (2002) e Labra (2002) encontraram fortes vínculos com a política tradicional entre os conselheiros da sociedade civil de Curitiba e Rio de Janeiro, respectivamente.

7 Necessitamos fazer uma ressalva proposta pela própria autora, que afirma que tal separação não pode tender ao rompimento, sob o risco de tornar pior o processo representativo (YOUNG, 2006). Também Urbinati (2006) defende que seja feita uma ratificação de extremos na teoria da representação.
}

Na diferenciação entre representante e representado encontra-se o inevitável viés de que jamais a vontade do segundo será satisfeita integralmente (MENDONÇA, 2004; YOUNG, 2006). Tal desacordo entre interesse e efetivação é facilmente percebido pelos representados. Porém, como nos alerta Mendonça (2004), há uma forma de representação em que o representado é totalmente envolvido pelo que o autor chama de "efeito de presença" do representante, de forma que o representado não mais percebe diferenças entre os interesses de seus delegados e seus próprios interesses. Tal fato, denominado de representação carismática, tende a substituir a vontade do "dominado" pela vontade do líder, destituindo e deslegitimando a representação política e prejudicando o pluralismo democrático (idem).

Ao diferenciar e separar representantes e representados, Young (2006) e outros autores, como Lüchmann (2007) e Urbinati (2006), procuram responder como se daria o processo de representação ao longo do mandato, apontando para uma resposta que tende a não deixar dúvidas de que uma representação legítima da sociedade civil requer, acima de tudo, uma conexão entre representantes e representados e uma conexão também entre os próprios representados 8 . Caso essas conexões não ocorram, a representação torna-se, inevitavelmente, pouco democrática (YOUNG, 2006). Ainda segundo a autora: "O principal problema normativo da representação é a ameaça de desconexão entre o representante único e os muitos que ele ou ela representa. Quando os representantes se tornam muito afastados, os eleitores perdem a percepção de que exercem influência sobre a produção de políticas, desafeiçoam-se e se abstêm da participação" (idem, p. 156).

Tais relações estariam incluídas no bojo de uma teoria formalista de representação política que considera como necessidades para sua legitimação mecanismos de prestação de contas e autorização dos representantes para exercerem seus mandatos, afastando-se de uma teoria meramente descritiva (MIGUEL, 2003). Ou seja: a questão da representação deve focar-se menos na distância entre representantes e representados e mais nas relações entre eles (PINTO, 2004). Pitkin (1979) é clara ao afirmar que "do modo como uma relação é estabelecida ou concluída, nada se deduz logicamente a respeito do que acontece

\footnotetext{
8 É nesse ponto que se diferenciam teoria participativa e teoria representativa de democracia. Apenas a primeira preocupa-se em analisar relações entre representados (LÜCHMANN, 2007).
} 
durante a relação, ou de como ela deve ser conduzida" (idem, p. 18). Desse modo, enquanto os cidadãos precisam engajar-se em um processo de mobilização coletiva que ative esses processos de autorização e prestação de contas, os representantes precisam ouvir esses atores e dar explicações a respeito de avaliações e ações que tomam nas instâncias representativas (YOUNG, 2006).

É evidente que para a ocorrência de tais relações necessita-se de uma sociedade civil ativa, já que a legitimidade da representação, então, valer-se-á, em grande medida, do grau de sua articulação (idem; LÜCHMANN, 2007). Talvez essa seja a grande limitação real dessa necessária articulação. A própria Young (2006) parte de um pressuposto de que desigualdades socioeconômicas alimentam desigualdades políticas, excluindo grupos minoritários das decisões e ferindo, portanto, o princípio democrático já citado anteriormente de inclusão da pluralidade de atores inerente a uma nação. Tal exclusão, concebida por Telles (1994) como um verdadeiro "apartheid social", acentuaria ainda mais as desigualdades socioeconômicas, criando, segundo Kerstenetzky (2003), um círculo vicioso extremamente nocivo à democracia, que só a participação seria capaz de romper (DEMO, 1993). Além da diminuição das desigualdades sociais, Silva (2003) acrescenta que se faz necessário também uma mudança na visão sobre o cidadão como consumidor para sua inserção na sociedade como executores e agentes de suas capacidades ${ }^{9}$. Dessa forma, a democracia seria, por si só, um estimulador da educação política dos cidadãos, em que o referido círculo vicioso daria lugar a um círculo virtuoso, de forma que quanto mais a sociedade participa, mais interessada e capacitada politicamente ela se torna (PATEMAN, 2002).

Outra questão que deve ser considerada em relação à sociedade civil, e que vem contestando empiricamente sua representação em espaços participativos, é que em seu interior existem tanto projetos políticos que tendem a ampliar a democracia como também projetos que deslegitimam a democracia (GURZA LAVALLE, HOUTZAGER \& CASTELLO, 2006) e esses espaços participativos não são imunes aos mesmos, como nos lembra Ferraz (2006). Estamos, portanto, diante de

\footnotetext{
9 Remetendo essa lógica para o Brasil, essas idéias adquirem proporções bastante preocupantes, tendo em vista a situação de desigualdade social e apatia política em que se encontra a sociedade brasileira, que tem raízes culturais de cidadania e inserção política extremamente ligadas a uma forte submissão às elites. Para compreender esse processo ao longo da história do Brasil, ver Carvalho (2004).
}

uma heterogeneidade nata que a sociedade civil possui. Tal constatação põe em xeque a idéia de que a sociedade civil seja o pólo das virtudes, e o Estado o mantenedor do mal, segundo uma visão maniqueísta questionada por Dagnino, Olvera e Panfichi (2006).

Mediante tais elementos, propor características que assegurem legitimidade à representação no interior dos conselhos gestores requer mais do que as sugestões viáveis, porém um tanto quanto subjetivas, de Young (2006). É preciso traçar uma configuração possível e mais enraizada à realidade em que se apresentam esses mecanismos participativos, tanto no que se refere à atuação do Estado, quanto à atuação da sociedade civil, para que tenhamos, enfim, uma luz direcionada aos conselhos gestores que aponte para um ideal legítimo de representação. Alguns autores já começam a apontar tal direção. A eles nos remeteremos a partir de agora.

\section{REPRESENTAÇÃO POLÍTICA EM CONSE- LHOS GESTORES: A BUSCA POR LEGITIMI- DADE}

A discussão sobre representação política nas experiências participativas é relativamente nova, como já citamos, especialmente no que se refere à configuração de sua legitimidade. Buscar apoio teórico na representação parlamentar ${ }^{10}$ para tal objetivo é inviável, tendo em vista a crise que vive esse tipo de representação, em que representantes e representados encontram-se cada vez mais distantes. Enquanto nesse modelo, eleitoral, a legitimidade da representação restringe-se ao mero ato eleitoral, em que "a responsabilidade do processo decisório fica restrita aos representantes escolhidos pelo sufrágio eleitoral" (LÜCHMANN, 2008, p. 88), no modelo participativo, de uma maneira geral, a legitimidade é assegurada pela "idéia de que as decisões políticas devem ser tomadas por aqueles que estarão submetidos a elas, por meio do debate público" (idem, p. 89), carecendo, como veremos, de critérios específicos para tal, como a relação entre os representantes e representados. Outra questão que diferencia os modelos de representação citados refere-se ao fato de, na democracia eleitoral, o governo eleito, mesmo não tendo sido escolhido pela vontade de todos, tem obrigação para com todos ${ }^{11}$. Em contrapartida, quando associações civis exercem o papel de representantes esta obrigação inexiste, mesmo que o discurso e as práticas destes atores

\footnotetext{
10 Como nos lembra Lüchmann (2008), no "modelo representativo" [parlamentar], a legitimidade encontra-se no ato eleitoral, ou seja, "a responsabilidade do processo decisório fica restrita aos representantes pelo sufrágio universal” (idem,p. 88).

11 E juntamente com tais obrigações, uma maior autonomia no processo decisório (FERRAZ, 2005, p.39).
} 
demonstrem a busca por igualdade de direito e justiça social (ABERS \& KECK, 2008). Pinto (2004) acrescenta que uma das limitações da democracia representativa é exatamente o fato de que não é considerada a diferença (étnica, social, entre outras) no momento da manifestação democrática, no caso, no momento do voto.

Os autores contemporâneos começam a levantar idéias sobre o tema da representação exercida pela sociedade civil. Tentam, como vimos com Young (2006), apresentar uma concepção de aproximação entre representantes e representados, e entre os próprios representados, para que essa representação seja legítima. Urbinati (2006) sugere, por sua vez, que para a representação ser democrática (entende-se, legítima) é necessário que o povo possa ter a possibilidade de interromper o mandato do representante quando sinta crise em sua representatividade. Além disso, as autoras ainda sugerem que a representação política requer igualdade básica de condições materiais. Lüchmann (2007) ressalta que, especificamente nos conselhos gestores, há certa confusão no que concerne aos critérios de legitimidade, ora atribuído aos atores com história de militância política, ora atribuído ao envolvimento das entidades representadas nos respectivos setores. Avritzer (2007) problematiza a questão argüindo sobre as formas contemporâneas de legitimidade da representação, concluindo que esta se dá pelo que chamou de finalidade e via processo.

Parece, portanto, promissora a pungente reestruturação do termo "legitimidade" para a representação política que emerge juntamente com seu novo formato institucional. As colocações de Gurza Lavalle, Houtzager e Castello (2006) de que o debate sobre essa "nova representação" e sua legitimidade institucional é incipiente e que poucos são os autores que se debruçam sobre o tema tende, pelo que estamos a perceber, a perder sentido, e tomara que assim seja.

Propostas concretas, objetivas, de condensar variáveis que proporcionem esta almejada legitimidade às instâncias participativas começam a surgir. Borba e Lüchmann (2008), por exemplo, ofereceram-nos uma considerável contribuição para a realização desse trabalho, já que indicam quatro possíveis variáveis que determinariam o grau de qualidade (entendamos "legitimidade") da representação da sociedade civil nos conselhos gestores. Seriam elas: $(i)$ o perfil dos representantes; (ii) a auto-referência quanto à representação no conselho; (iii) o mecanismo de autorização para tornar-se representante e (iv) o processo de prestação de contas com os seus representados durante o mandato. É nesses dois últimos aspectos que focaremos com mais profundidade as nossas análises.

Vários trabalhos vêm ressaltando a tese de que, para adquirir legitimidade, a representação nos conselhos gestores deve conter mecanismos coerentes de autorização dessa representação e prestação de contas permanente do representante para com os representados durante todo o mandato. Os argumentos de Lüchmann $(2007 ; 2008)$ indicam-nos que os conselhos gestores não possuem tais mecanismos estabelecidos. Assim, Avritzer (2007), Borba e Lüchmann (2008) e Lüchmann (2008) enfatizam tal questão questionando-se sobre até que ponto devemos reduzir a sociedade civil a certas organizações ou segmentos sociais já que, claramente, a escolha das entidades que representarão a sociedade civil nos conselhos não é universalista e depende da trajetória política dessas entidades (LABRA, 2002; BORBA \& LÜCHMANN, 2008; LÜCHMANN, 2008), da vontade do gestor (COELHO \& VERÍSSIMO, 2004) ou até mesmo da influência de partidos políticos (LABRA, 2002).

É interessante acrescentar aqui a discussão que Dagnino (2002) faz a respeito dos diferentes conceitos de participação que há entre o poder Executivo e a sociedade civil ativa e propositiva. Como vêm mostrando diversos estudos (TATAGIBA, 2002; LABRA, 2005; CORTES, 2007, entre outros), a esfera governamental tem apresentado resistência em dividir o poder com os conselhos gestores. Além disso, o Estado vem assumindo uma postura ambígua frente ao avanço democrático, denominado por Dagnino (2002; 2004) como "confluência perversa": ao mesmo tempo em que vem institucionalizando canais participativos, o Estado assume também uma agenda liberal que, entre outras coisas, transfere para as ONGs importantes funções estatais. Assim, as ONGs assumem-se representantes do povo quando, de certa forma, não o são, já que seu predomínio na conjuntura atual tende a responder anseios neoliberais e sua desvinculação com os movimentos sociais, remetendoas a uma despolitização (DAGNINO, 2002). A autora conclui que "por mais bem intencionadas que sejam, a atuação das ONG traduz fundamentalmente os desejos de suas equipes diretivas" (idem, p. 159).

De todo o modo, os estudos que, de alguma forma, vieram analisar a relação entre representantes e representados em conselhos gestores de políticas públicas, entre eles, principalmente, os conselhos de saúde, notaram um baixo grau de relacionamento (prestação de contas) dos representantes com suas bases ou mecanismos de autorização variados e discutíveis (CORREIA, 2000; LABRA, 2002; LABRA 
\& FIGUEIREDO, 2002; COELHO \& VERÍSSIMO, 2004; GERSCHMAN，2004; DAVID，2005; GUIZARDI \& PINHEIRO, 2006; BORBA \& LÜCHMANN, 2008). É certo que a legislação assegura a representação de algumas entidades nos conselhos de saúde, conforme a Resolução n. 333 do Conselho Nacional de Saúde (BRASIL, 2003) e sua autorização para o mandato, como coloca Avritzer (2007), referese à experiência da instituição com o tema. Porém, tal formato de escolha de segmentos ou organizações civis para representação nos conselhos leva a ambigüidades da representação da sociedade civil na medida em que reproduz a filtragem dos setores com maior poder socioeconômico e cultural, deslegitimando o espaço dos conselhos (LÜCHMANN, 2007; 2008). De fato, diversos estudos vêm constatando que os representantes da sociedade civil nos conselhos apresentam elevado nível socioeconômico e alto grau de escolaridade (FUKS, 2002; LABRA, 2002; LABRA \& FIGUEIREDO, 2002; GERSCHMAN, 2004; WENDHAUSEN, BARBOSA \& BORBA, 2006; VAN STRALEN et alii, 2006; BORBA \& LÜCHMANN, 2008, entre outros), retratando um elitismo presente também nos mecanismos tradicionais parlamentares de representação. Além disso, Coelho e Veríssimo (2004) notaram que as relações entre organizações civis e governos são cruciais para que aquelas sejam convidadas por estes a participarem do processo de formação do corpo do conselho de saúde, de modo que outras instituições, muitas vezes extremamente ativas e representativas da sociedade, ficam de fora por não possuírem vínculo prévio com os setores governamentais. Mais especificamente sobre a escolha dos representantes da entidade na representação de conselhos gestores, Borba e Lüchmann (2008) identificaram que quase $67 \%$ dos conselheiros entrevistados foram indicados pela entidade. Difícil imaginar uma relação sólida entre representantes e representados por meio de uma consistente prestação de contas quando desde o processo de autorização já há distanciamento entre os representantes com a base representada.

Além do perfil e da relação entre representantes e representados via autorização e prestação de contas, discutida acima, a chamada "pretensão de legitimidade", ou seja, os sentidos que os atores envolvidos atribuem à sua representação nos espaços representativos também é um pressuposto analítico a respeito da legitimidade da representação. Como lembra Gurza Lavalle, Houtzager e Castello (2006, p. 47), "a presunção pública de representar alguém não equivale à sua efetiva representação". Esses mesmos autores, no importante trabalho que realizaram em instituições civis de São Paulo sobre a autopercepção de representatividade dessas instituições, encontraram interessantes achados. Algumas instituições atribuíram sua representatividade a mecanismos símbolos da democracia tradicional, como eleição, afiliação e identidade. Outras, mais numerosas, inauguraram padrões novos de representatividade, o que não assegura o caráter democrático dos argumentos. Prestar serviços assistencialistas, para $23,4 \%$ das entidades entrevistadas, é o principal fator que lhes assegura uma representação legítima da população assistida. Além desse, proximidade e, principalmente, intermediação, foram citadas pela maioria das entidades como argumento de representatividade. A principal conclusão que tiramos dessas idéias é a de que essa variedade de argumentos "põem em xeque interpretações que desenvolvem modelos únicos de representações no seio das organizações civis" (idem, p. 55).

Também sob esse ponto de vista, Borba e Lüchmann (2008) analisaram a justificativa de representatividade de atores representantes de conselhos gestores e encontraram uma variedade grande de respostas entre os entrevistados. A resposta mais concentrada foi que o conselho é representativo porque "diversos segmentos são representados", com $12 \%$ de freqüência. $\mathrm{O}$ vínculo entre representantes e representados foi argumento de representatividade em apenas $1 \%$ dos entrevistados.

\section{CONCLUSÕES}

Procuramos pontuar as diversas concepções a respeito da representação no interior de espaços participativos buscando afinar a relação entre participação e representação da sociedade civil em novas instâncias de mediação entre sociedade civil e Estado, como os conselhos gestores de políticas públicas. Além disso, tentamos também expor algumas idéias a respeito das possíveis maneiras de tornar essa representação legítima, no sentido de incluírem-se setores da sociedade civil que de outra forma jamais seriam incluídos no processo deliberativo das políticas públicas. Com tais análises, procuramos obter bases teóricas a respeito da representação política em discussão na literatura e, então, proporcionar a pesquisadores desse campo uma leitura abrangente das discussões contemporâneas sobre participação e representação.

Fica claro, contudo, que as respostas que vêm sendo dadas às questões aqui levantadas seguem um caminho interessante, mesmo que insuficiente no momento para afirmar modelos ideais de representação em conselhos gestores. Cremos que a literatura analisada aqui, apesar de abrangente, poderá ser ampliada com o passar do tempo e poderá, no futuro, proporcionar repostas menos subjetivas e mais 
concretas sobre formas realmente legítimas de representação da sociedade civil em instâncias participativas de deliberação de políticas públicas.

De concreto, somente a certeza de que os conselhos gestores de políticas públicas vêm cumprindo um papel substancial no que diz respeito à mudança na cultura política da sociedade brasileira, que cada vez mais compreende que o papel do povo na democracia não se restringe ao mero voto eleitoral. Esse entendimento passa, invariavelmente, a uma concepção realmente democrática de representação política em instâncias participativas.

Marcelo Eliseu Sipioni (mesipioni@yahoo.com.br) é Mestre em Saúde Coletiva pela Universidade Federal do Espírito Santo (UFES) e Professor da Universidade Vila Velha (UVV-ES).

Marta Zorzal e Silva (mazorzal@gmail.com) é Doutora em Ciência Política pela Universidade de São Paulo (USP) e Professora do Departamento de Ciências Sociais da Universidade Federal do Espírito Santo (UFES).

\section{REFERÊNCIAS BIBLIOGRÁFICAS}

ABERS, R. N. \& KECK, M. E. 2008. Representando a diversidade: Estado, sociedade e "relações fecundas" nos conselhos gestores. Caderno CRH, Salvador, v. 21, n. 52.p. 99-112, jan.-abr. Disponível em: http://www.scielo.br/pdf/ccrh/v21n52/ a08v2152.pdf. Acesso em: 27.maio.2013.

AVRITZER, L. 1996. A moralidade da Democracia. São Paulo: Perspectiva.

2003. Limites e potencialidades da expansão democrática no Brasil. Trabalho apresentado no Fórum Social Brasileiro, ciclo de seminários "Agenda Pós-neoliberal: fazendo possível um outro mundo", realizado em Belo Horizonte, de 7 a 8 de novembro. Digit. Disponível em: http:// www.ibase.br/userimages/leonardo_ avritzer port.pdf. Acesso em: 27.maio.2013.

2006. Reforma política e participação no Brasil. In: AVRITZER, L. \& ANASTÁSIA, F. (orgs.). Reforma política no Brasil. Belo Horizonte: UFMG.

. 2007. Sociedade civil, instituições participativas e representação: da autorização à legitimação da ação. Dados, Rio de Janeiro, v. 50, n. 3, p. 443-464. Disponível em: http://www.scielo.br/pdf/ dados/v50n3/01.pdf. Acesso em: 26.maio.2013.

.2008. Instituições participativas e desenho institucional: algumas considerações sobre a variação da participação no Brasil democrático. Opinião Pública, Campinas, v. 14, n. 1, p. 43-64, jun.

BOBBIO, N. 2000. O futuro da democracia. $10^{\mathrm{a}} \mathrm{ed}$ São Paulo: Paz e Terra.

BORBA, J. \& LÜCHMANN, L. H. H. 2008. A representação politica nos Conselhos Gestores de Politicas Públicas. Trabalho apresentado no IV Congresso ALACIP, realizado na Universidad de Costa Rica, realizado em San José, de 5 a 7 de agosto. Digit.
CARVALHO, J. M. 2004. Cidadania no Brasil: o longo caminho. $6^{\text {a }}$ ed. Rio de Janeiro: Civilização Brasileira.

COELHO, V. S. P. \& VERÍSSIMO, J. 2004. Considerações sobre o processo de escolha dos representantes da sociedade civil nos conselhos de saúde de São Paulo. In: AVRITZER, L. (org.). A participação em São Paulo. São Paulo: UNESP.

CORREIA, M. V. C. 2000. Que controle social? Os conselhos de saúde como instrumento. Rio de Janeiro: Fiocruz.

CORTES, S. M. V. 2007. Viabilizando a participação em conselhos de política pública municipais: arcabouço institucional, organização do movimento popular e policy communities. In: HOCHMAN, G.; ARRETCHE, M. \& MARQUES, E. (orgs.). Políticas Públicas no Brasil. Rio de Janeiro: Fiocruz.

COSTA, S. 2002. As cores de Ercília: esfera pública, democracia, configurações pós-nacionais. Belo Horizonte: UFMG.

DAGNINO, E. 2002. Democracia, teoria e prática: a participação da sociedade civil. In: PERISSINOTTO, R. \& FUKS, M. (orgs.). Democracia: teoria e prática. Rio de Janeiro: Relume Dumará.

2004. Sociedade civil, participação e cidadania: de que estamos falando? In: MATO, D. (org.). Politicas de ciudadania y sociedad civil en tiempos de globalización. Caracas: FACES.

DAGNiNO, E.; OLVERA, A. J. \& PANFICHI, A. 2006. Para uma outra leitura da disputa pela construção democrática na América Latina. In: DAGNINO, E.; OLVERA, A. J. \& PANFICHI, A. (orgs.). A disputa pela construção democrática na América Latina. São Paulo: Paz e Terra. 
DAHL, R. A. 2001. Sobre a democracia. Brasília: UNB.

DAVID, C. T. N. 2005. Representantes e representados: relação entre conselheiros usuários, suas entidades e espaços descentralizados do Conselho Municipal de Saúde de Porto Alegre. Porto Alegre. Dissertação (Mestrado em Sociologia). Universidade Federal do Rio Grande do Sul.

DEMO, P. 2003. Participação é conquista. $2^{\mathrm{a}}$ ed. São Paulo: Cortez.

FERRAZ, A. T. R. 2005. Impactos da experiência conselhista sobre as atividades politicas $e$ organizativas dos movimentos sociais na saúde: o caso do movimento popular de saúde de Campinas/ São Paulo. Campinas. Tese (Doutorado em Ciências Sociais). Universidade Estadual de Campinas.

2006. Pensando a democracia e seu processo de adjetivação. Agália, Galiza (Espanha), v. 8586, p. 173-200.

2009. Cenários da participação política no Brasil: os conselhos gestores de políticas públicas. In: ZORZAL E SILVA, M. \& BRITO JUNIOR, B. T. (orgs.). Participação social na gestão pública: olhares sobre as experiências de Vitória-ES. São Paulo: Annablume.

FUKS, M. 2002. Participação política em conselhos gestores de políticas sociais no Paraná. In: PERISSINOTTO, R. \& FUKS, M. (orgs.). Democracia: teoria e prática. Rio de Janeiro: Relume Dumará.

GERSCHMAN, S. 2004. Conselhos Municipais de Saúde: atuação e representação das comunidades populares. Cadernos de Saúde Pública, Rio de Janeiro, v. 20, n. 6, p. 1670-1681, nov.-dez. Disponível em: http://www.scielo.br/pdf/csp/ v20n6/26.pdf. Acesso em: 27.maio.2013.

GUIZARDI, F. L. \& PINHEIRO, R. 2006. Dilemas culturais, sociais e políticos da participação dos movimentos sociais nos conselhos de saúde. Ciência e Saúde Coletiva, Rio de Janeiro, v. 11, n. 3, p. 797-805. Disponível em: http://www.scielo. br/pdf/csc/v11n3/30994.pdf. Acesso em: 27.maio.2013.

GURZA LAVALLE, A. 2003. Sem pena nem glória: o debate sobre a sociedade civil nos anos 1990. Novos Estudos, São Paulo, n. 66, p. 91-109, jul. Disponível em: http://www.fflch.usp.br/dcp/ assets/docs/Adrian/2003NovosEstudos SemPenaNemGloria.pdf. Acesso em: 27.maio.2013.
GURZA LAVALLE, A.; HOUTZAGER, P. P. \& CASTELLO, G. 2006. Representação política e organizações civis: novas instâncias de mediação e os desafios da legitimidade. Revista Brasileira de Ciências Sociais, São Paulo, v. 21, n. 60, p. 43-66, fev. Disponível em: http://www.scielo.br/ pdf/rbcsoc/v21n60/29760.pdf. Acesso em: 27.maio.2013.

KERSTENETZKY, C. L. 2003. Sobre associativismo, desigualdades e democracia. Revista Brasileira de Ciências Sociais, São Paulo, v. 18, n. 53, p. 131142, fev. Disponível em: http://www.scielo.br/pdf/ rbcsoc/v18n53/18082.pdf. Acesso em: 27.maio. 2013 .

LABRA, M. E. 2002. A qualidade da representação dos usuários nos Conselhos Distritais de Saúde do Rio de Janeiro e a dimensão associativa. Relatório Final de Pesquisa Estratégica. Rio de Janeiro: Fundação Oswaldo Cruz.

2005. Conselhos de saúde: dilemas avanços e desafios. In: LIMA, N. T.; GERSCHMMAN, S.; EDLER, F. C. \& SUÁREZ, J. M. (orgs.). Saúde e democracia: histórias e perspectivas do SUS. Rio de Janeiro: Fiocruz.

LABRA, M. E. \& FIGUEIREDO, J. S. A. 2002. Associativismo, participação e cultura cívica: o potencial dos conselhos de saúde. Ciência e Saúde Coletiva, Rio de Janeiro, v. 7, n. 3, p. 537-547.

LÜCHMANN, L. H. H. 2002. Os conselhos gestores de políticas públicas: desafios do desenho institucional. Revista Ciências Sociais Unisinos, São Leopoldo, v. 38, n. 161, p. 43-79, jul.-dez.

2007. A representação no interior das experiências de participação. Lua Nova, São Paulo, n. 70, p. 139-170. Disponível em: http://www.scielo. $\mathrm{br} / \mathrm{pdf} / \mathrm{ln} / \mathrm{n} 70 / \mathrm{a} 07 \mathrm{n} 70 . \mathrm{pdf}$. Acesso em: 27.maio.2013.

2008. Participação e representação nos Conselhos Gestores e no Orçamento Participativo. Caderno CRH, Salvador, v. 21, n. 52, p. 87-97, abr. Disponível em: http://www.scielo.br/pdf/ccrh/ v21n52/a07v2152.pdf. Acesso em: 27.maio.2013.

MENDES, C. V. R. 2007. Representação política e participação: reflexões sobre o déficit democrático. Katálysis, Florianópolis, v. 10, n. 2, p. 143-153, jul.-dez. Disponível em: http://www.scielo.br/pdf/ rk/v10n2/a02v10n2.pdf. Acesso em: 27.maio. 2013 .

MENDONÇA, D. 2004. Notas sobre o "efeito de presença" da representação. Revista Sociologia e 
Política, Curitiba, n. 23, p. 79-87, nov. Disponível em: http://www.scielo.br/pdf/rsocp/n23/ 24623.pdf. Acesso em: 27.maio.2013.

MIGUEL, L. F. 2003. Representação política em 3D: elementos para uma teoria ampliada da representação política. Revista Brasileira de Ciências Sociais, São Paulo, v. 18, n. 51, p. 123140, fev. Disponível em: http://www.scielo.br/pdf/ rbcsoc/v18n51/15989. Acesso em: 27.maio.2013.

PATEMAN, C.1992. Participação e teoria democrática. São Paulo: Paz e Terra.

PINTO, C. R. J. 2004. Espaços deliberativos e a questão da representação. Revista Brasileira de Ciências Sociais, São Paulo, v. 19, n. 54, p. 97113, fev. Disponível em: http://www.scielo.br/pdf/ rbcsoc/v19n54/a06v1954.pdf. Acesso em: 27.maio.2013.

PITKIN, H. F. 1979. O conceito de representação. In: CARDOSO, F. H. \& MARTINS, C. E. (orgs.). Política e Sociedade. São Paulo: Nacional.

2006. Representação: palavras, instituições e idéias. Lua Nova, São Paulo, n. 67, p. 15-47. Disponível em: http://www.scielo.br/pdf/ln/n67/ a03n67.pdf. Acesso em: 27.maio.2013.

ROUSSEAU, J. 1997. O Contrato Social. São Paulo: Nova Cultural. Coleção “Os Pensadores”.

SANTOS, B. S. 1999. Pela mão de Alice: o social e o político na pós-modernidade. São Paulo: Cortez.

SANTOS, B. S. \& AVRITZER, L. 2002. Para ampliar o cânone democrático. In: SANTOS, B. S. (org.). Democratizar a democracia: os caminhos da democracia participativa. Rio de Janeiro: Civilização Brasileira.

SAWARD, M. 2008. Representation and Democracy: revisions and possibilities. Sociology Compass, v.
2, n. 3, p. 1000-1013, May.

SCHUMPETER, J. 1984. Capitalismo, socialismo e democracia. Rio de Janeiro: J. Zahar.

SILVA, I. G. 2003. Democracia e participação na "Reforma" do Estado. São Paulo: Cortez.

TATAGIBA, L. 2002. Os conselhos gestores e a democratização das políticas públicas no Brasil. In: DAGNINO, E. (org.). Sociedade civil e espaços públicos no Brasil. São Paulo: Paz e Terra.

TELES, V. S. 1994. Sociedade civil e a construção de espaços públicos. In: DAGNINO, E. (org.). Os anos 90: política e sociedade no Brasil. São Paulo: Brasiliense.

URBINATI, N. 2006. O que torna a representação democrática? Lua Nova, São Paulo, n. 67, p. 191228. Disponível em: http://www.scielo.br/pdf/ln/ n67/a07n67.pdf. Acesso em: 27.maio.2013.

VAN STRALEN，C. J.; LIMA，A. M. D.; SOBRINHO, D. F.; SARAIVA, L. E. S.; VAN STRALEN, T. B. \& BELISÁRIO, S. A. 2006. Conselhos de Saúde: efetividade do controle social em municípios de Goiás e Mato Grosso do Sul. Ciência e Saúde Coletiva, Rio de Janeiro, v. 11, n. 3, p.621-632.

Disponível em: http://www.scielosp.org/pdf/csc/ v11n3/30978.pdf. Acesso em: 27.maio.2013.

WENDHAUSEN, A. L. P.; BARBOSA, T. M. \& BORBA, M. C. 2006. Empoderamento e recursos para a participação em conselhos gestores. Saúde e Sociedade, São Paulo, v. 15, n. 3, p. 131-144, set.-dez. Disponível em: http://www.scielo.br/pdf/ sausoc/v15n3/11.pdf. Acesso em: 27.maio.2013.

YOUNG, I M. 2006. Representação política, identidade e minorias. Lua Nova, São Paulo, n. 67, p. 139190. Disponível em: http://www.scielo.br/pdf/ln/ n67/a06n67.pdf/. Acesso em: 27.maio.2013.

\section{OUTRAS FONTES}

BRASIL. Ministério da Saúde. Conselho Nacional de Saúde. 2003. Resolução $n^{\circ} 333$ de 04 de novembro de 2003. Aprova as diretrizes para criação, reformulação, estruturação e funcionamento dos Conselhos de Saúde. Brasília. 


\title{
REFLECTIONS AND INTERPRETATIONS ABOUT PARTICIPATION AND REPRESENTATION IN PUBLIC POLICES MANAGEMENT COUNCILS
}

\author{
Marcelo Eliseu Sipioni and Marta Zorzal e Silva
}

This essay is based on the recent literature about representation on public polices management councils. There are several analyzes by various authors on the subject, however, it's necessary to think about the confluence of these ideas, in order to contribute to a minimum consensus (obviously not definitive) about the possibilities and limits of democratic exercise in management councils, need that this article aims to answer, at least in part. To develop this analysis, we review the literature in order to seek authors from different areas of knowledge that somehow deal in their works the theme of democratic theory and participation and representation, trying to observe convergences and counterpoints in their ideas to after launch issues minimally consensus on the subject. The authors analyzed make it clear that the discourses that permeate the issues of participation and representation have as background different democratic theories that almost throughout the last century conflict for hegemony: representative democracy and participatory democracy. Thus, the ideal that underpin the concepts studied here are expressed in different ways, according to the theory that underlies it. The fact is that participation and representation can be exercised both in a representative democracy and in a participatory democracy. However, have different meanings and practices. The public polices management councils are a kind of instance created to the exercise of participatory democracy. However, there is exerted indirect participation through representation. This concept, in turn, is strongly rooted to the ideals of representative democracy, making necessary to establish differences between represent (representative democracy) and represent (participatory democracy), so that counselors representatives of civil society in management councils not repeat the mistakes of the practice parliamentary representative, at the risk of driving the representation in these participatory instances to a distance that would undermine the exercise of participatory democracy in our country. It seems obvious the importance of establishing a relationship between representatives and represented that approach them. Thus, important points such as accountability and own way of choosing the representative for their entity appear to play a role interesting to legitimize the representation and make it different from parliamentary representation. Despite obstacles to the realization of a true participatory democracy, the management councils feed a changing political culture in Brazil, the culture of participation, that can replace our historical submission culture of the people to the power of the elites.

KEYWORDS: social participation; representation; representation; management council. 